\title{
Teriparatide in East Asian Postmenopausal Women with Osteoporosis in a Real-World Setting: A Baseline Analysis of the Asia and Latin America Fracture Observational Study (ALAFOS) [Corrigendum]
}

Chen $\mathrm{CH}$, Lim SJ, Oh JK, et al. Clin Interv Aging. $2020 ; 15 ; 111-121$.

During the publication process, two of the authors names were presented incorrectly on page 111 . The author list should be presented as:

\author{
Chung-Hwan Chen' \\ Seung-Jae Lim $^{2}$ \\ Jong-Keon $\mathrm{Oh}^{3}$ \\ Tsan-Wen Huang ${ }^{4}$ \\ Yu-Hong Zeng ${ }^{5}$ \\ Meng-Ting $\mathrm{Wu}^{6}$ \\ Hui-Lin Yang ${ }^{7}$ \\ Jason Pui-Yin Cheung ${ }^{8}$ \\ Ji Wan Kim ${ }^{9}$ \\ Jeong Hee $\operatorname{Han}^{10}$ \\ Li Huo"l \\ Tsung-Jung $\operatorname{Lin}^{12}$ \\ Gang Zhou' ' \\ Wen-Shuo $\mathrm{Wu}^{12}$
}

'Department of Orthopedics and Orthopedic Research Center, Kaohsiung Municipal Ta-Tung Hospital and Kaohsiung Medical University Hospital, College of Medicine, Kaohsiung Medical University, Kaohsiung City, Taiwan; ${ }^{2}$ Department of Orthopedic Surgery, Samsung Medical Center, Sungkyunkwan University School of Medicine, Seoul, South Korea; ${ }^{3}$ Department of Orthopedics, Korea University Guro Hospital, Seoul, South Korea; ${ }^{4}$ Department of Orthopaedic Surgery, Chang Gung Memorial Hospital, Chiayi, Taiwan; ${ }^{5}$ Department of Osteoporosis, Honghui Hospital, Xi'an Jiaotong University, Xian, People's Republic of China; ${ }^{6}$ Division of Neurosurgery, Department of Surgery, Cheng Hsin General Hospital, Taipei, Taiwan; ${ }^{7}$ Department of Orthopedics, The First Affiliated Hospital of Soochow University, Suzhou, People's Republic of China; ${ }^{8}$ Department of Orthopaedics and Traumatology, The University of Hong Kong, Hong Kong, People's Republic of China; ${ }^{9}$ Department of Orthopedic Surgery, Asan Medical Center, University of Ulsan, College of Medicine, Seoul, South Korea; ${ }^{10}$ Department of Medical Quality and Regulatory Affairs, Lilly Korea Ltd., Seoul, South Korea; ''Lilly China Drug Development and Medical Affairs Center, Lilly Suzhou Pharmaceutical Co. Ltd., Shanghai, People's Republic of China; ${ }^{2}$ Department of Medical Affairs, Eli Lilly and Company (Taiwan), Inc., Taipei, Taiwan

Clinical Interventions in Aging

\section{Publish your work in this journal}

Clinical Interventions in Aging is an international, peer-reviewed journal focusing on evidence-based reports on the value or lack thereof of treatments intended to prevent or delay the onset of maladaptive correlates of aging in human beings. This journal is indexed on PubMed Central, MedLine, CAS, Scopus and the Elsevier
Bibliographic databases. The manuscript management system is completely online and includes a very quick and fair peer-review system, which is all easy to use. Visit http://www.dovepress.com/ testimonials.php to read real quotes from published authors. 